\title{
Comparing spatial memory in two species of tit: Recalling a single positive location
}

\author{
SUSAN D. HEALY and JOHN R. KREBS \\ Edward Grey Institute of Field Ornithology, Oxford, England
}

\begin{abstract}
The performance of a food-storing species, the marsh tit (Parus palustris), was compared with that of a nonstorer, the blue tit ( $P$. caeruleus), in a spatial memory task in which birds had to return to a site where they had previously been allowed to eat part of a piece of peanut. No differences were found between species' overall performance, but increasing retention interval from $1 \mathrm{~min}$ to $24 \mathrm{~h}$ brought about a decrease in performance. The results are discussed in relationship to the hypothesis that food-storing birds have a specialized spatial memory capacity.
\end{abstract}

Some members of the avian families Paridae and Corvidae have been shown to store food and to use a longlasting and accurate spatial memory to relocate their hoards (Sherry, 1984, 1987; Balda, Bunch, Kamil, Sherry, \& Tomback, 1987). It has also been shown that in comparison with nonstorers, food-storing passerines (including storing members of the Paridae and Corvidae) have an enlarged hippocampal region relative to the size of the rest of the forebrain (Krebs, Sherry, Healy, Perry, \& Vaccarino, 1989; Sherry, Vaccarino, Buckenham, \& Herz, 1989). The hippocampal region in birds, as in mammals, appears to play a role in processing certain kinds of memory (Good, 1989), especially, according to some authors, spatial memory (Bingman, 1990; Bingman, Ioalé, Casini, \& Bagnoli, 1988a, 1988b; Sherry \& Vaccarino, 1989). These observations have led to the hypothesis that the larger hippocampus of food storers is associated with a specialization of spatial memory. In this paper and in companion papers (Hilton \& Krebs, 1990; Healy \& Krebs, in press; Krebs, Healy, \& Shettleworth, 1990; Krebs, Hilton, \& Healy, 1990), we compare the spatial memory of storing and nonstoring tits in order to identify the nature of the differences between them.

The tasks used to compare storing and nonstoring species cannot involve storage and retrieval of food itself (since the nonstoring species are unable to store food), so it has to be assumed that an appropriately designed memory task other than food-storing might reveal the capacities used by food-storing birds in retrieving their hoards. A problem is to identify the appropriate kinds of memory tasks that would capture the essence of the retrieval of stored food. In previous experiments, we used

\footnotetext{
We thank the Royal Society (J.R.K.), SERC (J.R.K. \& S.D.H.), St. Hilda's College, Oxford (S.D.H.), and St. John's College, Oxford (S.D.H.) for financial support. Sara Shettleworth provided valuable comments at all stages of this work. Marian Dawkins, Tim Guilford, and Andrew Hurly made useful comments on the manuscript. Mark Pagel and Jonathan Newman provided invaluable statistical advice. Correspondence should be addressed to Susan D. Healy at the Edward Grey Institute of Field Ornithology, South Parks Road, Oxford OX1 3PS, U.K.
}

a range of tasks, from standard procedures in animal psychology, such as delayed-matching-to-sample (Healy \& Krebs, in press) and the radial maze (Hilton \& Krebs, 1990 ), to tasks that have been designed specifically to resemble retrieval of stored food, such as "windowshopping" (Krebs, Healy, \& Shettleworth, 1990). In this paper, we compare food-storing marsh tits (Parus palustris) and nonstoring blue tits (Parus caeruleus) by using a procedure similar to window-shopping. In windowshopping, the bird is first allowed to see a piece of food behind one of a number of small "windows" distributed about a test room. Then, after a retention interval, it can obtain a reward by returning to the site where it saw the food. In this test phase of the experiment, all the windows in the room are open but are covered with a small cloth curtain so that the bird cannot detect the food without lifting the curtain. To perform above chance level, the bird has to remember the site where it initially saw food. This task shares with food-storing and retrieval the property of a bird's return to a specific site after an initial visit. There is some evidence that food-storing coal tits perform the task more accurately than nonstoring great tits (Krebs, Healy, \& Shettleworth, 1990), although the result is not robust to small procedural differences (Krebs, Hilton, \& Healy, 1990). Additionally, Shettleworth, Krebs, Healy, and Thomas (1990) showed that performance in window-shopping is degraded to some extent by the presence of the window, perhaps because the bird may not always know if there is a seed behind the window.

In this experiment, we used a procedure similar to window-shopping but without windows (Brodbeck, 1989). In Phase 1 of a trial, birds were allowed to eat part of a piece of peanut in one (chosen at random) of seven possible hiding sites in the test room. In Phase 2 of the trial, the bird had, after a retention interval, to return to the same site to finish the peanut. In Phase 2, all the sites were covered by a paper flap so that the birds could only make an accurate return by remembering the original site. As in window-shopping, the bird has to return to a feeding site on the basis of a single experience with the site. However, there are four different aspects of the procedure that 
might be expected to enhance performance relative to window-shopping: First, there are no windows; second, the bird spends longer at the target site (eating part of the peanut); third, it is positively reinforced at the site in Phase 1; and fourth, the bird visits only the rewarded site in Phase 1 and therefore does not have to distinguish between rewarded and nonrewarded sites.

\section{METHOD}

\section{Subjects}

The subjects were 4 marsh tits and 4 blue tits caught in deciduous woodland near Stanton St. John in Oxfordshire, U.K. Both species were kept individually indoors in $0.77 \times 0.44 \times 0.44 \mathrm{~m}$ wiremesh cages $(l \times w \times h)$, each connected to the experimental room by a remotely controlled door. Every day, the birds were fed a commercial insectivorous bird food mixture supplemented by boiled eggs, carrots, peanuts, sunflower seeds, and fly pupae, and were maintained on a 10:14-h light:dark cycle.

\section{Experimental Environment}

The experiments were run in a $3.75 \times 3.9 \times 2.4 \mathrm{~m}(1 \times w \times h)$ room adjacent to that in which the birds were held. The birds could fly into the experimental room through the eight connecting doors that were arranged in two rows on one of the $3.9-\mathrm{m}$ walls. One of the 3.75-m walls had a smoked Perspex window through which the birds could be observed, and all four walls had conspicuous visual cues in the form of colored tape or large colored cardboard symbols.

There were nine artificial "trees"' in the experimental room, each painted with bright colors in different patterns. These trees were $1.75-\mathrm{m}$ cut saplings set in white plastic umbrella stands or concrete bases, and each had several doweling perches $(10.0 \mathrm{~cm}$ long $\times$ $0.9 \mathrm{~cm}$ in diameter) set at random heights. Blocks of wood $(9.0 \mathrm{~cm}$ wide $\times 15.0 \mathrm{~cm}$ high $\times 4.0 \mathrm{~cm}$ thick) were hung on seven trees; in the middle of the face of each wooden block was a hole $(0.5 \mathrm{~cm}$ in diameter), and $4 \mathrm{~cm}$ below this hole was a perch $(5.5 \mathrm{~cm}$ long $\times 0.9 \mathrm{~cm}$ in diameter) on which the bird could sit to examine the contents of the hole. The blocks were placed at varying heights on the trees, and, since the trees were arranged approximately in a semicircle facing the wall with the doors, the face of each block could be seen from all of the doors. The remaining two trees were placed near the doors but did not obscure the view of the blocks from the doors.

Each inspection of the hole in a block by the bird while it was on the perch below the hole ("look") was recorded.

\section{Training}

The food bowls were removed from the birds' cages between 1700 and $1800 \mathrm{~h}$ daily for the duration of the experiment. Trials began at $1000 \mathrm{~h}$, which was about $3 \mathrm{~h}$ after the daylight cycle began. Several minutes after each trial, the birds were given bowls of fresh food and water. Training for the experiment was accomplished in two ways: First, a block of wood, such as that used in the experiment, was put into each bird's cage. A whole peanut was wedged into the hole in the block so that the bird could not immediately remove it. The bird pecked at the peanut until a large proportion was eaten and was then usually able to extract, in one piece, the remainder of the peanut from the hole. All of the birds removed and ate the peanut on Day 1 of training.

The second part of training consisted of teaching the birds to fly through the doors after the lights over their cages were turned off and they were allowed to fly into the lighted experimental room. During this phase of training, the trees had blocks on them, all of which contained a peanut. The birds took between 16 and 20 days to learn to fly in and out by using the lights to guide them. Following this phase, a block containing a peanut covered with a flap of paper $(2.5 \times 3.5 \mathrm{~cm})$ was placed in each bird's cage. The piece of paper was lightly stuck to the block so that it covered the peanut completely. All of the birds were easily able to remove the paper. The peanut could not be seen through the paper, nor was it possible to see whether the hole was empty or full. The use of smell or other food-related cues in locating food stores was found to be unimportant by Shettleworth and Krebs (1982) and thus was not tested in the experiment. The birds began the experiment proper on the day after the peanut was covered with paper.

\section{Experimental Trials}

Trials were conducted in a manner similar to training, with the following exceptions: First, only one of the seven blocks contained a pioce of peanut (the positive site), and, unlike the remaining blocks, the rewarded site was labeled with a small sticker placed just above the peanut. This sticker was used to make the site with the peanut clearly noticeable. The aim of these features was for the bird to visit only the rewarded site, thus removing the possibility of interference between the memories of empty sites visited and of the site containing the food. Second, each trial was divided into two phases. During Phase 1, the bird was allowed to enter the room, locate the block with the peanut, and peck at and eat the peanut for $30 \mathrm{sec}$ (i.e., the bird was allowed to eat some, but not all, of the peanut). This increased the amount of time the bird spent at the site and might therefore have increased its likelihood of remembering the site when it was allowed to return to finish the food. The lights were then turned off so that the bird would leave the room. A predetermined retention interval elapsed before the bird was allowed back into the experimental room (Phase 2). In Phase 2, the hole in each of the potential sites was covered with a flap of paper (a Post-it label) so that the bird could not see its contents. Only the original, rewarded, site, however, contained a peanut in Phase 2. When the bird had located this site and removed the flap of paper, it was allowed to eat the remainder of the peanut. The block containing the peanut was chosen at random each day. One trial was conducted per day, and the number of visits made by each bird in Phase 2 to potential sites before finding the positive site was recorded.

The retention interval between Phases 1 and 2 was varied over the course of the experiment in the following order: $30 \mathrm{~min}$ (20-30 trials), $24 \mathrm{~h}$ (14 trials), $30 \mathrm{~min}$ ( 7 trials), $1 \mathrm{~min}$ (14 trials). All birds completed the two blocks of 30-min trials and 24-h trials. Three of the 4 marsh tits and 3 of the 4 blue tits also completed the 1-min trials. Although trials were conducted in the same order for all birds, it was possible to test for order effects by comparing the birds' performances in the two 30 -min blocks.

\section{RESULTS}

The data were analyzed in two ways: (1) by comparing the number of visits the birds took to find the peanut in the retrieval phase for the different retention intervals and (2) by comparing the frequency distributions of visits to find the peanut with expected distributions under the null hypothesis of random sampling without replacement.

\section{Learning: Improvement With Experience}

To test for improvement in performance (number of visits to find the peanut) in the first treatment (the 20-30 trials of 30-min retention interval), we compared the performance of each bird on the initial 10 trials with its performance on the last 10 trials by using an analysis of variance (ANOVA) with repeated measures. There was no difference between the species $[F(1,6)=0.71, p=.43]$, there was a significant effect of trials $[F(1,6)=15.96$, 
Table 1

Mean Number of Looks $( \pm S E)$ to Find Food on the First and Last 10 Trials of the Initial Exposure to the 30-min Retention Interval

\begin{tabular}{lcc}
\hline Species & First 10 Trials & Last 10 Trials \\
\hline Marsh tits & $3.5 \pm 0.4$ & $2.7 \pm 0.4$ \\
Blue tits & $3.2 \pm 0.5$ & $2.2 \pm 0.2$ \\
\hline
\end{tabular}

Table 2

Mean Number of Looks $( \pm S E)$ on the First and Second Blocks of Trials with the 30-min Retention Interval

\begin{tabular}{lcc}
\hline Species & Block 1 & Block 2 \\
\hline Marsh tits & $3.0 \pm 0.4$ & $2.3 \pm 0.6$ \\
Blue tits & $2.6 \pm 0.3$ & $2.7 \pm 0.5$ \\
\hline
\end{tabular}

$p=.007]$, and there was no significant interaction between species and trials $[F(1,6)=0.16, p=.69]$. The performance of both species improved with experience (see Table 1).

To evaluate possible order effects, a repeated measures ANOVA was conducted on performance on the two blocks of trials with the 30-min retention interval (see Table 2). There were no significant differences between the species $[F(1,6)=0.004, p=.95]$ or between the two blocks $[F(1,6)=1.17, p=.32]$, and there was no significant interaction between the two main effects $[F(1,6)=2.75$, $p=.15]$. Consequently, for subsequent analyses, data from the last 7 days from Block 1 were combined with the 7 days from Block 2. Each of the three retentioninterval treatments thus contained 14 days' data.

\section{Number of Visits to Find the Food}

We used one-sample $t$ tests (one-tailed) to compare the observed number of visits to find the peanut with the expected value from sampling without replacement, which is four visits. The results are presented in order of increasing retention interval for each species (see Figure 1).

The performance of the marsh tits was better than the random expectation on trials with a 1 -min retention interval $[t(2)=4.902, p=.02]$ and on the 30-min trials $[t(3)=$ $2.761, p=.04]$, but was not better than the random expectation on trials with a retention interval of $24 \mathrm{~h}[t(3)=$ $1.93, p=.07]$. The following are the numbers of marsh tits that performed significantly better than chance at each of the respective retention intervals: $3 / 3,3 / 4,1 / 4$.

The blue tits' performance was better than chance after a 1 -min retention interval $[t(2)=3.575, p=.04]$ and after a 30-min interval $[t(3)=5.697, p=.011]$. This species also performed at a level significantly better than chance after a 24 h retention interval $[t(3)=5.036$, $p=.015]$. The following are the numbers of blue tits that performed significantly different from chance at each of the respective retention intervals: $2 / 3,4 / 4,1 / 4$.

\section{Effect of Retention Interval}

A nested ANOVA with repeated measures was used to determine if there was an effect of retention interval on the number of visits to find the peanut and if the effect differed between the two species. The birds were nested within each species, whereas retention intervals were treated as repeated measures. Two ANOVAs were calculated, since 2 of the birds did not complete trials with the 1-min retention interval. The first ANOVA included all 8 birds and looked at the difference between the first two treatments ( $30 \mathrm{~min}$ and $24 \mathrm{~h}$ ). This analysis showed no difference between the species $[F(1,6)=0.14, p=$ .73], a significant effect of retention interval $[F(1,6)=$ $14.89, p=.008]$, and no significant interaction between the two effects $[F(1,26)=0.001, p=.90]$.

The second ANOVA compared all three treatments ( $1 \mathrm{~min}, 30 \mathrm{~min}$, and $24 \mathrm{~h}$ ), but only 3 individuals from each species contributed data for this analysis. There was no difference between the species $[F(1,4)=0.92$, $p=.39]$, there was a significant difference between retention intervals $[F(2,8)=4.94, p=.04]$, and there was no significant interaction between species and retention interval $[F(2,8)=2.00, p=.22$; see Figure 1].

Overall, the analyses show that the number of visits that birds of both species take to find the food increases with increasing retention interval. The decline in performance was most marked when retention interval was increased from $30 \mathrm{~min}$ to $24 \mathrm{~h}$, with both species responding similarly. When the data for the three retention intervals were compared, the decline was still significant but much less marked.

\section{Distribution of Visits to Find the Food}

We also compared the birds' performances with a null hypothesis of random search by examining the frequency distributions of visits to find the peanut at the three retention intervals. For each individual bird, there were insufficient data to construct a frequency distribution, so we combined data across birds within a species. Our as-

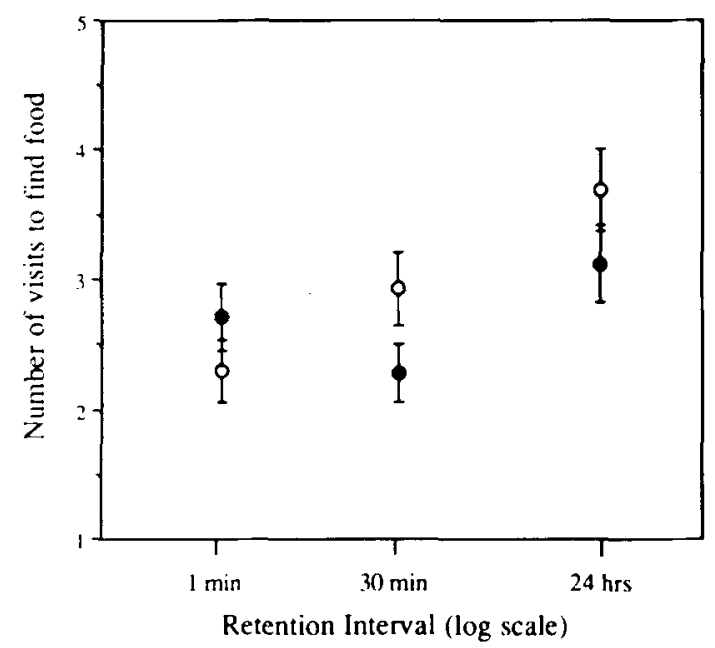

Figure 1. The number of vitts made by blue tits (closed drclea) and marsh tits (open circles) to find food in Phese 2, followtis three different retention intervals. The values are means and sandard errors. There were 14 trials from each bird; $n=3$ for both spectes at $1 \mathrm{~min}$, and $n=4$ for both species for $30 \mathrm{~min}$ and $24 \mathrm{~h}$. 
sumption that trials, rather than birds, are independent data points should be borne in mind when interpreting the levels of significance.

If the birds search at random but avoid revisits within a trial (which were, in any case, extremely infrequent), the distribution of visits to find the peanut will follow a "sampling without replacement" distribution. On the first visit, the probability is 1 out of $7(p=.143)$. The probability of finding the peanut on the second visit is 1 out of $6(p=.167)$ multiplied by the probability of not having found the peanut on the first visit $(1-p)$. This is equal to $1 / 6 \times 6 / 7$, which equals $1 / 7$. Similar calculations for each successive visit show that the probability is always .143 when there are seven possible sites.

Figure 2 shows the distributions for the two species compared with the null hypothesis for the three retention intervals. The marsh tits' performance differed from that expected from sampling without replacement at all three retention intervals, but blue tits did so only at 1 and $30 \mathrm{~min}$ [marsh tits $-1 \mathrm{~min}, \chi^{2}(6)=34.3, p=.0001 ; 30 \mathrm{~min}$, $\chi^{2}(6)=36.2, p=.0001 ; 24 \mathrm{~h}, \chi^{2}(6)=14.9, p=.02$; blue tits $-1 \mathrm{~min}, \chi^{2}(6)=19.9, p=.003 ; 30 \mathrm{~min}, \chi^{2}(6)=$ $\left.40.9, p=.0001 ; 24 \mathrm{~h}, \chi^{2}(6)=9.5, p=.15\right]$.

Figure 2 also shows that the observed distributions for both blue tits and marsh tits are positively skewed. The data suggest that the first visits were guided by memory: even if the birds made an error on the first visit, they tended to be above chance on the second visit. We also examined the spatial distribution of errors on the first visit when the peanut was found on the second visit in order to see if first-visit errors tended to be to sites next to the correct one. There appears to be a difference between the species: the errors made by blue tits were distributed at random with respect to the correct site, whereas marsh tits tended to visit the site next to the correct one. Combining data across retention intervals, the observed percentage of errors to the nearest neighbor for blue tits was $36 \%$ [expected 28\%; $\chi^{2}(1)=1.25, p>.25$ ], whereas for marsh tits it was $54 \%$ [expected $30 \% ; \chi^{2}(1)=10.48$, $p<.005]$. We also looked to see if first-visit errors tended to be made to the site that had been the correct one the previous day. For neither species did there seem to be such an effect (12\% and $9 \%$ of trials for the blue tits and marsh tits, respectively, versus expected values of $14 \%$ ).

\section{DISCUSSION}

The main results are as follows:

1. Some individuals of both species were able to return to a site where they had eaten part of a peanut at above chance level after retention intervals of $1 \mathrm{~min}, 30 \mathrm{~min}$, and $24 \mathrm{~h}$.

2. Performance of both species declined with increasing retention intervals.

3. There were no significant differences between the two species in overall performance, although there was a suggestion that the spatial patterns of errors differed between the species.
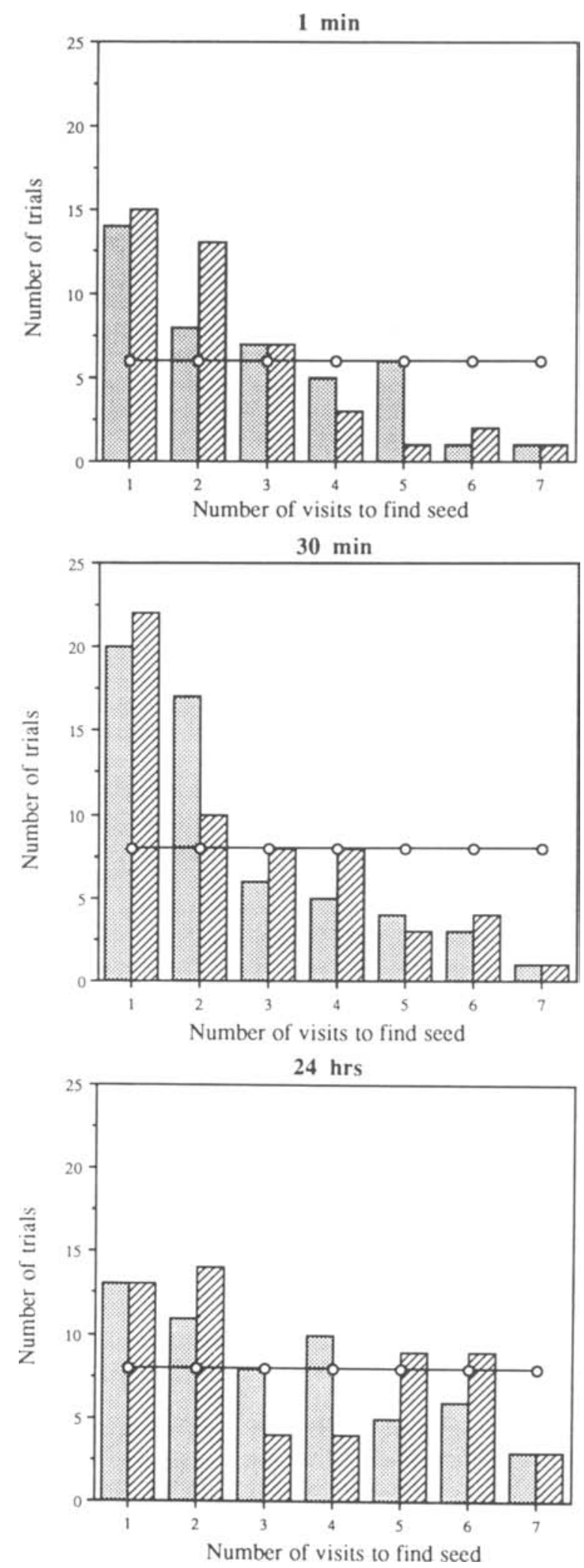

Figure 2. Frequency distributions of the number of visits to find the rewarded ste. Retention intervals are $1 \mathrm{mim}, 30 \mathrm{~min}$, and $24 \mathrm{~h}$. Values are species totals (ahaded bars = marnh tits; hatched bars - blue tits). Supertimposed on the data are predicted values for an approximation to a anpling without replecement distribution (opeen circles joined by line). 
The failure to find differences between the species in overall performance could be either because there are no differences in spatial memory between storing and nonstoring tits, as represented by these two species, or because the experimental procedure did not detect the differences. With regard to the first possibility, the hippocampal region of food-storing birds is relatively larger than that of nonstorers, and the species used in this experiment conformed to this pattern. This region of the brain is apparently concerned with processing spatial memories rather than with other (e.g., motor) aspects of food storing (Sherry \& Vaccarino, 1989), although its exact significance is not known. One possibility is that the special feature of food-storing memory is the ability to associate spatial locations with the act of storing food, and the effect of hippocampal damage on other spatial tasks (Sherry \& Vaccarino, 1989) is tangential to the question of hippocampal specialization of food storers.

Turning to the second possibility, the memory task used in the present study was chosen because it appeared to capture some of the features of food storing, especially the return of a bird to a site after a single experience, and it is similar to one in which food-storing chickadees (Parus atricapillus) appear to perform as well as they do in retrieving their own hoards (Shettleworth et al., 1990). It is possible that the task did not present either species with difficulty in remembering food locations, but this seems unlikely, as both species' performance declined with increasing retention interval. In addition, when the birds' performances are compared with the predictions for a random search, only some of the individuals perform at better than chance at each of the retention intervals. Another possibility is that the task was sufficiently similar to the foraging of a nonstorer that it was not a good method for distinguishing between the abilities of nonstorers and the hypothesized specialized abilities of storers. Finally, it could be that the difference in hippocampus size is not associated with an ability of a food storer to retain spatial information for a greater length of time but rather with an ability to remember a larger amount of spatial information. Although food-storing tits are able to remember storage sites for up to 28 days (Hitchcock \& Sherry, 1990 ), the majority of stored food is retrieved within a much shorter period both in the wild and in the laboratory (T. A. Hurly, November 9, 1990, personal communication; Stevens \& Krebs, 1986).

Brodbeck, Burack, \& Shettleworth (in press) used a technique similar to the present one to investigate memory in food-storing black-capped chickadees. They used three, instead of seven, locations and compared performances on trials involving blocks differing in visual characteristics with performances on trials involving visually similar blocks (as in the present experiment). They found that after a retention interval of $30 \mathrm{~min}$, chickadees performed at above chance level with visually distinctive, but not with visually similar, sites. The fact that some birds in the present experiment were above chance in both 30-min and 24-h trials might be taken to suggest that chickadees have poorer spatial memories than either marsh tits or blue tits, but we think it more likely that procedural differences are important. For example, because Brodbeck et al. used only three sites, a single error in a trial reduced the birds' performance to chance level. Nevertheless, Brodbeck et al.'s finding that visually distinctive locations enhance performance suggests that interference might be a factor that limited performance in the present procedure.

The present experiment resembles a spatial delayedmatching-to-sample task. In comparison with the rats studied by Roitblat \& Harley (1988), our birds remembered over very long retention intervals. However, in recent years, there has been a reassessment of the memory capabilities of standard laboratory animals such as the rat and pigeon. For example, less than 10 years ago, results were reported that showed that pigeons had difficulty remembering spatial locations for more than a few seconds (Wilkie, Spetch, \& Chew, 1981), but now it is apparent that this species can remember locations after several hours (Spetch \& Honig, 1988; Wilkie \& Willson, 1989)there is even some evidence for spatial memory after $24 \mathrm{~h}$ (R. J. Willson \& D. M. Wilkie, February 22, 1991, personal communication). This difference between earlier and more recent conclusions may partly reflect a change from the use of arbitrary tasks (e.g., pecking at an array of lights; Wilkie, 1986) to the use of tasks that relate more closely to natural foraging (e.g., searching for food in different parts of a room; Spetch \& Edwards, 1986). Performance in the "natural" tasks may be better than in the arbitrary tasks either because the former exploit inborn dispositions to learn or, more simply, because they incorporate features, such as wide separation of sites and richness of landmarks, that make the task easier for the animal to solve. Studies of food-storing corvids offer support for better performance on a "natural" task compared with an arbitrary task: three corvid species have been shown to remember spatial information (i.e., where their caches were hidden) for at least 7 days (Balda \& Kamil, 1989), whereas two of the same species did not perform above chance after $80 \mathrm{sec}$ in an operant delayednonmatching-to-sample (DNMTS) task in which the birds were required to peck at lighted keys (Olson, 1989). The provision of "natural" tasks may not be the sole route to achieving long retention. Zentall, Steirn, \& JacksonSmith (1990), for example, also used a DNMTS design with lighted keys, and their pigeons performed better than Olson's food-storing corvids: the pigeons were above chance with delays of up to an hour.

In summary, we suggest that two aspects of spatial memory should perhaps be distinguished in comparisons of storing and nonstoring tits. The first is the capacity to remember spatial information for long periods of time, which may not be exclusive to food storers. By choosing appropriate tasks such as the present one, both storers and nonstorers show this ability. The second aspect of spatial memory is the ability to retain, for quite brief periods of time, spatial information about many sites where food has 
been stored. To test this, future comparative experiments should focus on requiring birds to recall large amounts of spatial information rather than on testing the effects of retention interval alone.

\section{REFERENCES}

Balda, R. P., Bunch, K. G., Kamil, A. C., Sherry, D. F., \& Tомваск, D. F. (1987). Cache site memory in birds. In A. C. Kamil, J. R. Krebs, \& H. R. Pulliam (Eds.), Foraging behavior (pp. 645666). New York: Plenum.

Balda, R. P., Kamil, A. C. (1989). A comparative study of cache recovery by three corvid species. Animal Behaviour, 38, 486-495.

Bingman, V. (1990). Spatial organization in birds. In D. Olton \& R. Kesner (Eds.), Neurobiology of comparative cognition (pp. 423 . 447). Hillsdale, NJ: Erlbaum.

Bingman, V., Ionlé, P., Casini, G., Bagnoli, P. (1988a). Hippocampal ablated homing pigeons are impaired in the time taken to return home following release. Joumal of Comparative Physiology: A, 163, 559-563.

Bingman, V., Ionlé, P., Casini, G., \& Bagnoli, P. (1988b). Intact acquisition of spatial reference memory but impaired homing performance in pigeons following hippocampal ablation. Behavioral Brain Research, 27, 179-187.

Brodbeck, D. R. (1989). Memory for trial-unique food locations in chickadees. Unpublished master's thesis, University of Toronto.

Brodbeck, D. R., Burack, O. R., \& Shettleworth, S. J. (in press). One-trial associative memory in black-capped chickadees. Journal of Experimental Psychology: Animal Behavior Processes.

Good, M. (1989). The role of the avian hippocampus in learning and memory. Unpublished doctoral dissertation, University of York, York, U.K.

HeALY, S. D., \& KREBs, J. R. (in press). Delayed-matching-to-sample by marsh tits and great tits. Quarterly Joumal of Experimental Psychology.

Hilton, S. C., \& Krebs, J. R. (1990). Spatial memory of four species of Parus: Performance in an open-field analogue of a radial maze. Quarterly Journal of Experimental Psychology, 42B, 345-368.

Hitchcock, C. L., SherRy, D. F. (1990). The duration of memory for stored food in the black-capped chickadee. Animal Behaviour, 38 , 701-712.

Krebs, J. R., Healy, S. D., Shettleworth, S. J. (1990). Spatial memory of Paridae: Comparison of a storing and a non-storing species, Parus ater and Parus major. Animal Behaviour, 39, 1127-1137.

Krebs, J. R., Hilton, S. C., \& Healy, S. D. (1990). Spatial memory in food-storing birds: Adaptive specialization in brain and behavior? In G. Edelman, W. E. Gall, \& M. W. Cowan (Eds.), Signal and sense: Local and global order in perceprual maps (pp. 475-498). New York: Neuroscience Institute.

Krebs, J. R., Sherry, D. F., Healy, S. D., Perry, V. H., \& VACCARINo, A. L. (1989). Hippocampal specialization of food-storing birds. Proceedings of the National Academy of Sciences (USA), 86, 1388-1392.
OLson, D. (1989). Comparative spatial memory in birds. Unpublished doctoral dissertation, University of Massachusetts, Amherst.

RoITblat, H. L. , HARLEY, H. E. (1988). Spatial delayed matchingto-sample performance by rats: Learning, memory and proactive interference. Journal of Experimental Psychology: Animal Behavior Processes, 14, 71-82.

SHERRY, D. F. (1984). Food storage by black-capped chickadees: Memory for the location and contents of caches. Animal Behaviour, 32 , 451-464.

SherRY, D. F. (1987). Spatial memory in birds. In P. Ellen \& C. ThinusBlanc (Eds.), Cognitive processes and spatial orientation in animals and man (pp. 305-321). Dordrecht, The Netherlands: Martinus Nijhoff.

SherRY, D. F., V ACCARINo, A. L. (1989). Hippocampal aspiration disrupts cache recovery in black-capped chickadees. Behavioral Neuroscience, 103, 308-318.

Sherry, D. F., Vaccarino, A. L., Buckenham, K., Herz, R. S. (1989). The hippocampal complex of food-storing birds. Brain, Behavior \& Evolution, 34, 308-317.

ShetTleworth, S. J., \& KREBS, J. R. (1982). How marsh tits find their hoards: The role of site preference and spatial memory. Journal of Experimental Psychology: Animal Behavior Processes, 8, 354-375.

Shettleworth, S. J., Krebs, J. R., Healy, S. D., Thomas, C. M. (1990). Spatial memory of food-storing tits (Parus ater and P. atricapillus): Comparison of memory in storing and non-storing tasks. Journal of Comparative Psychology, 104, 71-81.

SPETCH, M. L., \& Edwards, C. A. (1986). Spatial memory in pigeons (Columba livia) in an open-field feeding environment. Joumal of Comparative Psychology, 100, 266-278.

SPETCH, M. L., \& HonIG, W. K. (1988). Characteristics of pigeons' spatial working memory in an open-field task. Animal Learning \& Behavior, 16, 123-131.

Stevens, T. A., \& Krebs, J. R. (1986). Retrieval of stored seeds by marsh tits Parus palustris in the field. Ibis, 128, 513-525.

WILKIE, D. M. (1986). Delayed matching of key location: A useful paradigm for the study of short-term spatial memory in birds. In $\mathrm{H}$. Ouellet (Ed.), Acta XIX Congressus Internationalis Ornithologici (Vol. 2, pp. 2069-2074). Ottawa: University of Ottawa Press.

WILKIE, D. M., SPETCH, M. L., \& ChEW, L. (1981). The ring dove's short-term memory capacity of spatial information. Animal Behaviour, 29, 639-641.

WILKIE, D. M., WILLSON, R. J. (1989). Pigeons' (Columba livia) spatial reference memory is stable over long retention intervals. Bulletin of the Psychonomic Society, 27, 271-273.

Zentall, T. R., Steirn, J. N., Jackson-Smith, P. (1990). Memory strategies in pigeons' performance of a radial-arm-maze analog task. Joumal of Experimental Psychology: Animal Behavior Processes, 16, 358-371.

(Manuscript received May 16, 1991; revision accepted for publication October 7, 1991.) 